\title{
Pharmacokinetic and Bioequivalence Study Evaluating a New Paracetamol/Caffeine Formulation in Healthy Human Volunteers
}

\section{Dongzhou J. Liu ${ }^{1 *}$, Mitchell Kotler ${ }^{1}$ and Scott Sharples ${ }^{2}$}

${ }^{1}$ Medical Affairs and New Products Research and Development, GlaxoSmithKline, Parsippany, NJ 07054, USA

${ }^{2}$ Celerion, 2420 W Baseline Rd, Tempe, AZ 85283, USA

\begin{abstract}
Purpose: Aim of this study was to evaluate the bioequivalence and clinical pharmacokinetics of newly developed paracetamol $500 \mathrm{mg}$ and caffeine $65 \mathrm{mg}$ combination (PANADOL ${ }^{\circledR}$ EXTRA ADVANCE product), compared with currently marketed conventional paracetamol/caffeine caplet (PANADOL EXTRA ${ }^{\circledR}$ product) in fasted and semi-fed states.

Methods: Thirty subjects were enrolled and all completed this 4-way crossover study. Serial blood samples were collected pre-dose until 10-hours post-dose for each period. Plasma samples were assayed for paracetamol and caffeine concentration using HPLC/MS methods. PK parameters were computed using non-compartmental model. Linear mixed-effect model was used to analyze logarithmically transformed $A \cup C_{0-\infty}, A C_{0-t}$ and $C_{\max }$ as well as $A \cup C_{0-30 \min }$ and $A \cup C_{0-60 \min }$ values $T_{\max }$ was analyzed by signed rank test on within-subject differences. Time to reach minimum therapeutic concentration in plasma of $4 \mu \mathrm{g} / \mathrm{ml}\left(\mathrm{T}_{4}\right)$ for paracetamol was evaluated. The AEs were also assessed. Ratios of $\mathrm{AUC}_{0-\infty}, \mathrm{AUC}_{0-\mathrm{t}}$, and $\mathrm{C}_{\max }$ were compared for new formulation vs. PANADOL EXTRA ${ }^{\circledR}$ in fasted and semi-fed states, and analyzed for bioequivalence as determined by $90 \%$ confidence intervals (CI90\%).
\end{abstract}

Results: Bioequivalence was established between these two formulations in both fasted and semi-fed states, as the ratios were within 0.8-1.25, except the $C_{\text {max }}$ of paracetamol in fasted state. In addition, the new formulation showed significantly greater early absorption (AUC $C_{0.70}$ and $A \cup C_{0 . m i n}$ ), as well as significantly shorter $T_{\text {max }}$, for both paracetamol and caffeine compared to PANADOL EXTRA ${ }^{\circledR}$ in fasted and semi-fed states. Based on $\mathrm{T}_{4}$, paracetamol absorption was twice as fast for the new formulation as compared to the corresponding conventional caplet in the fasted and fed states. The new formulation was safe and well tolerated.

Conclusions: The new Panado ${ }^{\circledR}$ Extra Advance formulation is bioequivalent to the currently marketed conventional formulation. Both paracetamol and caffeine are absorbed significantly faster with the new formulation compared to Panado ${ }^{\circledR}$ Extra product.

Keywords: Paracetamol/Acetaminophen; Caffeine; Bioavailability; Bioequivalence; Pharmacokinetics; Drug absorption

\section{Introduction}

Paracetamol (also known as acetaminophen) is a non-opioid widely distributed as an over-the-counter (OTC) drug for treating pain and reducing fever. It has both analgesic and antipyretic properties and is used for the treatment of mild and moderate pain. Although the precise mechanism of paracetamol has not been established, data suggests that central prostaglandin synthetase inhibition plays a large role [1]. Unlike NSAIDs, paracetamol does not inhibit the peripheral generation of prostaglandins and exhibit a clinical anti-inflammatory effect. Paracetamol does not alter the generation of prostaglandins in gastric mucosa [2] and, therefore, it is particularly suitable for patients with a history of GI disease or on concomitant medication where peripheral prostaglandin inhibition would be undesirable.

Caffeine is a common adjuvant for analgesic drugs such as paracetamol or acetylsalicylic acid [3-6]. The mechanism of action of caffeine is not fully understood, but involves nonselective antagonism of adenosine receptors [7], e.g., by counteracting adenosine, caffeine reduces resting cerebral blood flow between $22 \%$ and $30 \%$ [8]. Study suggests that caffeine induces changes in mood [9] which are probably due to its psychotropic actions and which may influence pain perception. Recently it has been demonstrated in an experimental pain model that the addition of caffeine $130 \mathrm{mg}$ enhances and prolongs the analgesic effect of paracetamol $1000 \mathrm{mg}$ [10]. A new paracetamol/ caffeine formulation was designed to deliver a faster dissolving and more quickly absorbed paracetamol/caffeine product. The formulation is based on OPTIZORB $^{\circledR}$ technology which includes well-defined amounts of calcium carbonate, alginic acid, and other ingredients to improve tablet disintegration and dissolution of both paracetamol and caffeine, and therefore provide improved absorption kinetics such as greater early absorption. The caplet core incorporates alginic acid in addition to calcium carbonate. It is postulated that calcium alginate, formed by the reaction of calcium ions with alginic acid in the acidic environment of the stomach, combine with carbon dioxide generated from calcium carbonate, facilitate the formation of a uniform suspension of fine particles with increased surface area leading to enhanced dissolution [11].

This study was conducted to evaluate the bioequivalence and clinical pharmacokinetics (PK) of the new formulation, PANADOL ${ }^{\circledR}$ EXTRA ADVANCE, in comparison to the currently marketed conventional

*Corresponding author: Dongzhou Jeffery Liu, Medical Affairs and New Products Research and Development, GlaxoSmithKline, Parsippany 1500 Littleton Rd Parsippany, NJ, USA, Tel: 973-889 4468; Fax: 973-889 2460; E-mail: jeffery.d.liu@ gsk.com

Received October 17, 2011; Accepted December 03, 2011; Published December 05, 2011

Citation: Liu D, Kotler M, Sharples S (2011) Pharmacokinetic and Bioequivalence Study Evaluating a New Paracetamol/Caffeine Formulation in Healthy Human Volunteers. J Bioequiv Availab 3: 251-257. doi:10.4172/jbb.1000095

Copyright: (c) 2011 Liu D, et al. This is an open-access article distributed under the terms of the Creative Commons Attribution License, which permits unrestricted use, distribution, and reproduction in any medium, provided the original author and source are credited. 
caplet, PANADOL EXTRA ${ }^{\circledR}$, for paracetamol and caffeine absorption in both fasted and semi-fed states.

\section{Materials and Methods}

\section{Study design}

The study was conducted in accordance with the ethical principles of Declaration of Helsinki [October, 1996], ICH Guideline for Good Clinical Practice (GCP) [July, 1996], and other applicable regulations. The study was initiated after approval by MDS Pharma Services Institutional Review Board. Subjects were recruited from the site's database of potential healthy volunteers, referrals and Institutional Review Board approved advertising. All subjects were informed with objectives, treatments, potential risks, dates and activities during the clinical part of study. A written consent form was signed by each enrolled subject.

This single-center, randomized, open-label, four-way crossover PK study compared a new formula and a currently-marketed formula of paracetamol + caffeine in terms of the rate and extent of absorption in 30 healthy subjects in fasted and semi-fed (as defined to start the treatment 2 hours after the meal) states.

Over the course of the nine-day confinement period, each subject received four single doses of $1000 \mathrm{mg}$ paracetamol + $130 \mathrm{mg}$ caffeine. Each subject received all four treatment/diet regimens in the order specified by the randomization schedule based on a William Square design.

Subjects ate breakfast 2 hours before dosing for the semi-fed state and were restricted from having breakfast in the morning for the fasted state. In addition, no food or drink was allowed after midnight for the fasted state. The content of all the meals was standardized with respect to protein, carbohydrate and fat content, and the timings of meals and drinks were standardized. A wash-out period of 48 hours was chosen between adjacent doses to allow for elimination of any metabolites.

\section{Study population}

Thirty healthy male or female subjects aged between 18 to 55 years meeting the inclusion criteria of having BMI between $19-28 \mathrm{~kg} /$ $\mathrm{m}^{2}$, in good general health with no clinically significant or relevant abnormalities of medical history, physical examination or laboratoryvalues were randomized to treatment. All subjects completed the study. The exclusion criteria included intolerance or hypersensitivity to the study drug, subjects taking any prescription/ herbal/ OTC medication 7 days prior to dosing, use of any drug known to introducing enzymes 30 days prior to screening, smokers who smoked more than 5 cigarettes a day, subjects who donated blood within 3 months of the screening visit or donated more than $1500 \mathrm{ml}$ of blood within the previous 12 months, subjects who were vegetarian, and subjects who had undertaken any unusually strenuous physical activity within $24 \mathrm{hrs}$ prior to screening and admission.

\section{Study drugs}

The test product was new PANADOL ${ }^{\circledR}$ EXTRA ADVANCE formulation (single dose comprised of two caplets totaling 1000 $\mathrm{mg}$ paracetamol $+130 \mathrm{mg}$ caffeine) and the reference product was PANADOL EXTRA $^{\circledR}$ (single dose comprised of two caplets totaling $1000 \mathrm{mg}$ paracetamol + $130 \mathrm{mg}$ caffeine; UK Product License No: 00071/0306). The treatments were taken with $200 \mathrm{ml}$ of water.

\section{Blood sampling}

The PK blood samples (approximately $5 \mathrm{ml}$ ) were collected either from an indwelling cannula or venapuncture (situated in a forearm vein), at pre-dose and at $0.25,0.50,0.75,1,1.25,1.5,2,3,4,5,6,7,8$ and 10 hours post-dose in each treatment period. When a cannula was used, an $1 \mathrm{ml}$ discard was taken from the cannula prior to sampling and the cannula was flushed after sampling with approximately $1 \mathrm{ml}$ heparinized saline. The nominal time (the time the blood samples was taken relative to the actual dosing time) was recorded. An explanation was given for any blood sample taken outside of the set sampling times (an acceptable blood sampling time was considered \pm 2 minutes of preset sampling times).

\section{Sample assay}

Blood samples were centrifuged at approximately 3000 revolutions per minute $(\mathrm{rpm})$ at $4^{\circ} \mathrm{C}$ for approximately 15 minutes. Approximately $2.5 \mathrm{ml}$ plasma was separated from each sample and was transferred equally into two $5 \mathrm{ml}$ polypropylene screw top tubes. Plasma samples were stored in tubes labeled with the study number, randomization number, study session and time point of the blood sample and were frozen at approximately $-20^{\circ} \mathrm{C}$ within 1 hour of sampling.

Paracetamol and caffeine in plasma were analyzed by a validated high performance liquid chromatographic tandem mass spectrometric (LC-MS/MS) method developed at Celerion. Sample preparation was achieved by liquid-liquid extraction method. For analysis respective deuterated compounds were used as internal standards (IS). Paracetamol and IS were extracted using a mobile phase of acetonitrile and $0.1 \%$ formic acid in water (15: 85) and analyzed on AQUASIL C18 column ( $5 \mu \mathrm{m}, 50 \times 3.0$ mm, Thermo Electron Corporation). For caffeine and its IS, mobile phase comprised of methanol and $0.1 \%$ formic acid (25:75) and $\mathrm{ACE}^{\circledR} \mathrm{C} 18(5 \mu \mathrm{m}, 50 \times 3.0 \mathrm{~mm}$, Advanced Chromatography Technologies) column was employed. The ions were detected using HPLC-MS/MS with an AB MDS Sciex API 4000 or 5000 detector.

For paracetamol, the method was validated over a concentration range $50-10,000 \mathrm{ng} / \mathrm{mL}$ with a limit of quantitation $50 \mathrm{ng} / \mathrm{mL}$. Intraand inter-batch precision of paracetamol ranged from 2.2 to $6.8 \%$ with accuracy (bias) varying between $-2.4 \%$ to $6.4 \%$ indicating good precision and accuracy. A validation range of $20-5000 \mathrm{ng} / \mathrm{mL}$ was used for caffeine. Intra- and inter-batch precision of caffeine ranged from 0.8 to $9.6 \%$ with accuracy (bias) varying between $-9.3 \%$ to $3.6 \%$ indicating good precision and accuracy. Average analytical recovery of caffeine was $35.6 \%$ and for IS was $18 \%$. Caffeine was found to be stable in plasma for 24 hours at ambient temperature under white light for short term stability, for 175 days at $-20^{\circ} \mathrm{C}$ for long term stability and after 133 hours for post-preparative stability.

\section{Pharmacokinetic calculations}

The non-compartmental method of analysis was used for evaluating the primary and secondary PK parameters for paracetamol and caffeine absorption in fasted and semi-fed states. The primary PK parameters included area under the concentration time curve to the last quantifiable sample $\left(\mathrm{AUC}_{0-\mathrm{t}}\right)$, area under the concentration time curve between zero and infinity $\left(\mathrm{AUC}_{0-\infty}\right)$, and maximum measured plasma concentration after single dose $\left(\mathrm{C}_{\max }\right)$. The secondary $\mathrm{PK}$ parameters included area under the concentration time curve between zero and 30 minutes $\left(\mathrm{AUC}_{0-30 \mathrm{~min}}\right)$, area under the concentration 
Citation: Liu D, Kotler M, Sharples S (2011) Pharmacokinetic and Bioequivalence Study Evaluating a New Paracetamol/Caffeine Formulation in Healthy Human Volunteers. J Bioequiv Availab 3: 251-257. doi:10.4172/jbb.1000095

time curve between zero and 60 minutes $\left(\mathrm{AUC}_{0-60 \mathrm{~min}}\right)$, time to reach maximum drug concentration $\left(\mathrm{T}_{\max }\right)$ and time concentration greater than $4 \mu \mathrm{g} / \mathrm{ml}$ for paracetamol $\left(\mathrm{T}_{4}\right)$. Values for $\mathrm{AUC}_{0-\mathrm{t}}$ were calculated by the trapezoidal method. Values for $\mathrm{AUC}_{0-\infty}$, were calculated as $\mathrm{AUC}_{0-\mathrm{t}}$ $+\mathrm{C}_{t} / \mathrm{Kel}$, where $\mathrm{C}_{\mathrm{t}}$ was the last quantifiable concentration, and Kel was the apparent terminal elimination rate constant determined by least squares regression analysis during the terminal log-linear phase of the concentration-time curve. $\mathrm{AUC}_{0-30 \mathrm{~min}}$ and $\mathrm{AUC}_{0-60 \mathrm{~min}}$ were the area under the plasma concentration time curve from zero to 30 minutes or 60 minutes calculated by the trapezoidal method. $\mathrm{T}_{4}$ for paracetamol was derived and analyzed in the same way as the 30 and 60 minute AUC parameters.

\section{Statistics}

The primary analysis was performed to compare the two formulations for bioequivalence with respect to paracetamol and caffeine. Bioequivalence is accepted if the $90 \%$ confidence interval for the ratio of new/current of each primary PK variable lies within the range $0.8-1.25$ [13]. This criterion was applied separately for both fasted and semi-fed states. Using the data from the fasted state, a linear mixed effects model was fit to $\log \mathrm{AUC}_{0-\mathrm{t}}$ (as the dependent variable), with treatment and period as fixed effects and subject as a random effect. Least squares estimates of treatment means were calculated and a $90 \%$ confidence interval (CI) for the treatment difference was computed. The treatment difference of the new vs current product and its CI was exponentiated to obtain the ratio of the geometric means and its CI. The same analysis was then performed on the data from the semi-fed state. The parameters $\mathrm{C}_{\max }$ and $\mathrm{AUC}_{0-\infty}$ were analyzed in exactly the same way as $\mathrm{AUC}_{0-\mathrm{t}}$. These primary analyses were performed on the values of $\log \mathrm{AUC}_{0-\mathrm{t}}, \log \mathrm{C}_{\max }$, and $\log \mathrm{AUC}_{0-\infty}$ that was determined based on unadjusted concentrations.
In the secondary analysis, the parameters $\mathrm{AUC}_{0-30 \mathrm{~min}}$ and $\mathrm{AUC}_{0}$ 60 min were analyzed with the same mixed model on log-transformed values as the primary analysis. However, the confidence intervals were compared against a lower limit of 1.00 (not the limits of $[0.8,1.25]$ ) because this was a superiority comparison. The parameter $\mathrm{T}_{\max }$ was analyzed by a nonparametric signed rank test on the within-subject differences to compare treatments (new vs. current product). The median treatment difference was calculated. The parameter $\mathrm{T}_{4}$ (mean values) was also analyzed with the same mixed model as the primary analysis, but without any log transformation. Only subjects having parameter values from both treatments were included in the analysis of these parameters. This analysis was performed separately for the fasted and semi-fed states. $\mathrm{T}_{4}$ was also analyzed with the same mixed model as the primary parameters, but without any log transformation.

The safety and tolerability of the new PANADOL ${ }^{\circledR}$ EXTRA ADVANCE caplets were compared to that of the conventional caplets by adverse event (AE) reporting.

\section{Results}

\section{Demographics}

Out of 82 subjects screened, 30 (20 females and 10 males) were randomized, and all 30 completed all four periods. Mean age ( \pm SD) was $32.9 \pm 7.82$ years with a range of $21-54$ years; Mean BMI $( \pm$ SD) was $25.22( \pm 1.46) \mathrm{kg} / \mathrm{m}^{2}$ with a range of $22-28 \mathrm{~kg} / \mathrm{m}^{2} ; 29(96.7 \%)$ subjects were White and 1 was Black or African American (3.3\%). Data from all the subjects were included in the final PK analysis.

\section{Pharmacokinetic results}

The mean paracetamol PK parameters $\left(\mathrm{C}_{\max }, \mathrm{AUC}_{0-\mathrm{t}}, \mathrm{AUC}_{0-\infty}\right.$ $\mathrm{AUC}_{0-30 \mathrm{~min}}$ and $\mathrm{AUC}_{0-60 \mathrm{~min}}$ ) for the two formulations, in both fasted and semi-fed states are presented in Table 1. The corresponding

\begin{tabular}{|c|c|c|c|c|c|c|}
\hline \multirow{4}{*}{ Parameter } & \multicolumn{3}{|c|}{ Fasted } & \multicolumn{3}{|c|}{ Semi-Fed } \\
\hline & \multicolumn{2}{|c|}{ Means ${ }^{[1]}$} & Ratio & \multicolumn{2}{|c|}{ Means ${ }^{[1]}$} & \multirow{3}{*}{$\begin{array}{c}\text { Ratio } \\
{[90 \% \mathrm{Cl}]}\end{array}$} \\
\hline & New & Current & \multirow{2}{*}[90\%\mathrm{Cl}]{} & New & Current & \\
\hline & $(\mathrm{N}=30)$ & $(\mathrm{N}=30)$ & & $(\mathrm{N}=30)$ & $(\mathrm{N}=30)$ & \\
\hline $\mathrm{C}_{\max }$ & \multirow{2}{*}{17.36} & \multirow{2}{*}{14.46} & 1.20 & \multirow{2}{*}{15.12} & \multirow{2}{*}{15.18} & 1.00 \\
\hline$(\mu \mathrm{g} / \mathrm{ml})$ & & & {$[1.11,1.30]$} & & & {$[0.93,1.07]$} \\
\hline$A \cup C_{0-t}$ & \multirow{2}{*}{53.08} & \multirow{2}{*}{49.59} & 1.07 & \multirow{2}{*}{48.57} & \multirow{2}{*}{47.38} & 1.03 \\
\hline$(\mu \mathrm{g} \cdot \mathrm{hr} / \mathrm{ml})$ & & & {$[1.05,1.10]$} & & & {$[1.00,1.05]$} \\
\hline$A \cup C_{0-\infty}$ & \multirow{2}{*}{57.54} & \multirow{2}{*}{53.97} & 1.07 & \multirow{2}{*}{52.95} & \multirow{2}{*}{51.80} & 1.02 \\
\hline$(\mu \mathrm{g} \cdot \mathrm{hr} / \mathrm{ml})$ & & & {$[1.04,1.09]$} & & & {$[1.00,1.05]$} \\
\hline $\mathrm{AUC}_{0-30 \min }$ & \multirow{2}{*}{3.74} & \multirow{2}{*}{1.28} & 2.93 & \multirow{2}{*}{1.25} & \multirow{2}{*}{0.16} & 7.68 \\
\hline$(\mu \mathrm{g} \cdot \mathrm{hr} / \mathrm{ml})$ & & & {$[2.23,3.84]$} & & & {$[4.59,12.85]$} \\
\hline$A \cup C_{0-60 \mathrm{~min}}$ & \multirow{2}{*}{11.37} & \multirow{2}{*}{6.63} & 1.72 & \multirow{2}{*}{6.93} & \multirow{2}{*}{2.31} & 3.00 \\
\hline$(\mu \mathrm{g} \cdot \mathrm{hr} / \mathrm{ml})$ & & & {$[1.46,2.02]$} & & & {$[2.17,4.14]$} \\
\hline
\end{tabular}

[1] Geometric means are the exponentiated least squares means of log-transformed variables

Table 1: Pharmacokinetic parameters of paracetamol in fasted and semi-fed states $\left(\right.$ New $=$ PANADOL ${ }^{\circledR}$ EXTRA ADVANCE; Current $=$ currently-marketed PANADOL $\operatorname{EXTRA~}^{\circledR}$. 
Citation: Liu D, Kotler M, Sharples S (2011) Pharmacokinetic and Bioequivalence Study Evaluating a New Paracetamol/Caffeine Formulation in Healthy Human Volunteers. J Bioequiv Availab 3: 251-257. doi:10.4172/jbb.1000095

\begin{tabular}{|c|c|c|c|c|c|c|}
\hline \multirow{4}{*}{ Parameter } & \multicolumn{3}{|c|}{ Fasted } & \multicolumn{3}{|c|}{ Semi-Fed } \\
\hline & \multicolumn{2}{|c|}{ Means ${ }^{[1]}$} & Ratio & \multicolumn{2}{|c|}{ Means ${ }^{[1]}$} & \multirow{3}{*}{$\begin{array}{c}\text { Ratio } \\
{[90 \% \mathrm{Cl}]}\end{array}$} \\
\hline & New & Current & \multirow{2}{*}[90\%\mathrm{Cl}]{} & New & Current & \\
\hline & $(\mathrm{N}=30)$ & $(\mathrm{N}=30)$ & & $(\mathrm{N}=30)$ & $(\mathrm{N}=30)$ & \\
\hline $\mathrm{C}_{\max }$ & \multirow{2}{*}{3.74} & \multirow{2}{*}{3.44} & 1.08 & \multirow{2}{*}{3.51} & \multirow{2}{*}{3.42} & 1.03 \\
\hline$(\mu \mathrm{g} / \mathrm{ml})$ & & & {$[1.045,1.125]$} & & & {$[0.986,1.068]$} \\
\hline$A \cup C_{0-t}$ & \multirow{2}{*}{21.85} & \multirow{2}{*}{20.98} & 1.04 & \multirow{2}{*}{20.52} & \multirow{2}{*}{20.07} & 1.02 \\
\hline$(\mu \mathrm{g} \cdot \mathrm{hr} / \mathrm{ml})$ & & & {$[1.020,1.064]$} & & & {$[0.999,1.046]$} \\
\hline$A \cup C_{0-\infty}$ & \multirow{2}{*}{31.65} & \multirow{2}{*}{30.79} & 1.03 & \multirow{2}{*}{30.44} & \multirow{2}{*}{30.23} & 1.01 \\
\hline$(\mu \mathrm{g} \cdot \mathrm{hr} / \mathrm{ml})$ & & & {$[0.990,1.067]$} & & & {$[0.963,1.052]$} \\
\hline$A \cup C_{0-30 \min }$ & \multirow{2}{*}{0.78} & \multirow{2}{*}{0.38} & 2.05 & \multirow{2}{*}{0.26} & \multirow{2}{*}{0.09} & 2.97 \\
\hline$(\mu \mathrm{g} \cdot \mathrm{hr} / \mathrm{ml})$ & & & {$[1.699,2.484]$} & & & {$[2.119,4.154]$} \\
\hline$A \cup C_{0-60 \min }$ & \multirow{2}{*}{2.52} & \multirow{2}{*}{1.80} & 1.40 & \multirow{2}{*}{1.56} & \multirow{2}{*}{0.69} & 2.28 \\
\hline$(\mu \mathrm{g} \cdot \mathrm{hr} / \mathrm{ml})$ & & & {$[1.268,1.552]$} & & & {$[1.786,2.905]$} \\
\hline
\end{tabular}

[1] Geometric means are the exponentiated least squares means of log-transformed variables

Table 2: Pharmacokinetic parameters of caffeine in fasted and semi-fed states (New $=$ PANADOL ${ }^{\oplus}$ EXTRA ADVANCE; Current $=$ currently-marketed PANADOL EXTRA $^{\oplus}$.

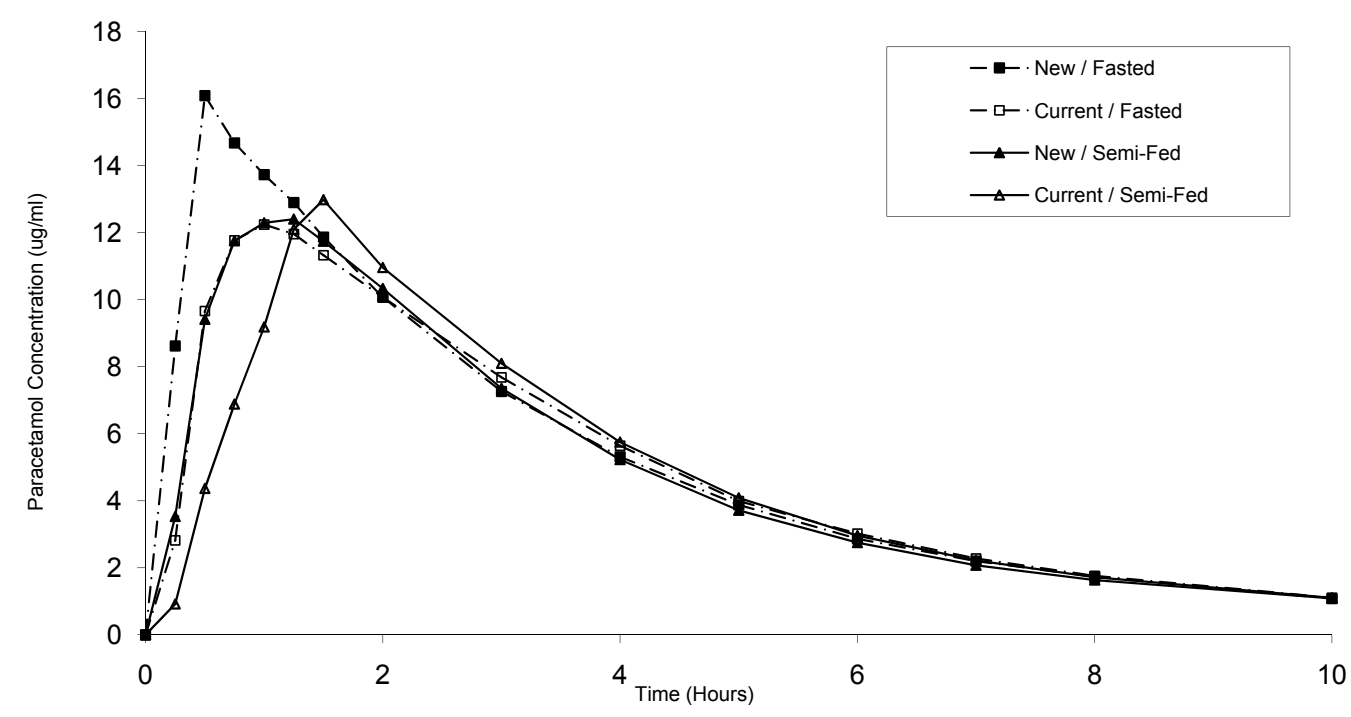

Figure 1: Mean plasma paraacetamol concentrations after single-dose oral administration of 1000mg paracetamol + 130mg caffeine from PANADOL ${ }^{\circledR}$ EXTRA ADVANCE (New) and PANADOL EXTRA ${ }^{\circledR}$ (Current) to 30 healthy human subjects under fasted and semi fed conditions.

mean caffeine PK parameters are presented in Table 2. The plots for mean paracetamol plasma concentration in fasted and semi-fed states for these formulations are presented in Figure 1. The corresponding plots of mean caffeine plasma concentration of these formulations are presented in Figure 2.

For both paracetamol and caffeine, the $90 \%$ confidence intervals for the ratios of $\mathrm{AUC}_{0-\infty}, \mathrm{AUC}_{0-\mathrm{r}}$, and $\mathrm{C}_{\max }$ for the two formulations, in both fasted and semi-fed states, all lied within the bioequivalence boundaries $[0.80,1.25]$, except for paracetamol $\mathrm{C}_{\max }$ in the fasted state, which was $[1.11,1.30]$ with the mean ratio of 1.20 .

The new formulation showed significantly greater early absorption $\left(\mathrm{AUC}_{0-30 \mathrm{~min}}\right.$ and $\left.\mathrm{AUC}_{0-60 \mathrm{~min}}\right)$ for both paracetamol and caffeine compared to the conventional caplets $(\mathrm{P}<0.0001)$. In the fasted state, the ratios of $\mathrm{AUC}_{0-30 \mathrm{~min}}$ and $\mathrm{AUC}_{0-60 \mathrm{~min}}$ between the new formulation and PANADOL EXTRA ${ }^{\circledR}$ were in 2.9 and 1.7 for paracetamol, and 2.0 and 1.4 for caffeine, respectively. In the semi-fed state, the ratios of $\mathrm{AUC}_{0-30 \mathrm{~min}}$ and $\mathrm{AUC}_{0-60 \mathrm{~min}}$ between these two formulations were 7.7 and 3.0 for paracetamol, and 3.0 and 2.3 for caffeine, respectively.

The results for $\mathrm{T}_{\max }$ and $\mathrm{T}_{4}$ values are listed in Table 3. The median $\mathrm{T}_{\max }$ values of paracetamol for the new formulation and the current conventional formulation were 0.50 hours and 0.99 hours in the fasted state, and 1.00 hours and 1.25 hours in the semi-fed state, respectively. In the nonparametric analysis, $\mathrm{T}_{\max }$ for paracetamol was statistically significantly shorter for the new formulation by about 15 minutes in 
Citation: Liu D, Kotler M, Sharples S (2011) Pharmacokinetic and Bioequivalence Study Evaluating a New Paracetamol/Caffeine Formulation in Healthy Human Volunteers. J Bioequiv Availab 3: 251-257. doi:10.4172/jbb.1000095

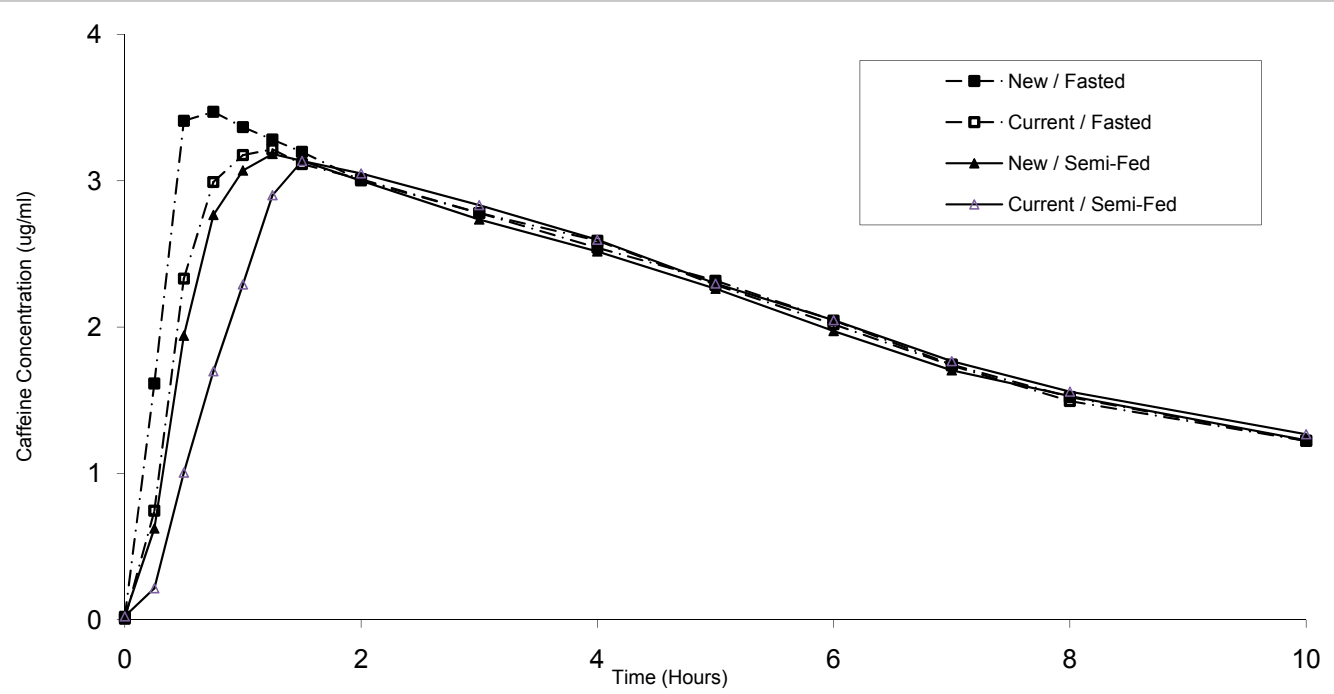

Figure 2: Mean plasma caffeine concentrations after single dose oral administration of $1000 \mathrm{mg}$ paracetamol + $130 \mathrm{mg}$ caffeine from PANADOL ${ }^{\circledR}$ EXTRA ADVANCE (New) and PANADOL EXTRA ${ }^{\circledR}$ (Current) to 30 healthy human subjects under fasted and semi fed conditions.

\begin{tabular}{|c|c|c|c|c|c|c|c|c|}
\hline \multirow{2}{*}{ Term } & \multicolumn{4}{|c|}{$\begin{array}{l}\text { Time (hours) } \\
\text { Fasted State }\end{array}$} & \multicolumn{4}{|c|}{$\begin{array}{l}\text { Time (hours) } \\
\text { Semi-Fed State }\end{array}$} \\
\hline & New & Current & Diff. & P-value & New & Current & Diff. & $\mathrm{P}$-value \\
\hline $\mathrm{T}_{4}{ }^{1}$ & 0.17 & 0.37 & -0.20 & $<.0001$ & 0.36 & 0.73 & -0.36 & $<.0001$ \\
\hline $\mathrm{T}_{\max }{ }^{2}$ & 0.50 & 0.99 & -0.26 & $<.0001$ & 1.00 & 1.25 & -0.24 & $=0.0136$ \\
\hline
\end{tabular}

${ }^{1}$ Time for T4 is mean time to reach plasma paracetamol concentration equal or greater than $4 \mu \mathrm{g} / \mathrm{ml}$ based on Least Square means from Proc Mixed of SAS and P-value is associated with the t-test.

${ }^{2}$ Time for Tmax is median time to reach maximum plasma paracetamol concentration and P-value is associated with Wilcoxon Signed Rank test for median of differences (New - Current) across all subjects.

Table 3: Time to reach plasma paracetamol concentration at therapeutic level (4ug/ml) and Tmax for new and current Panadol Extra in fasted and semi-fed state.

\begin{tabular}{|c|c|c|c|c|c|c|c|c|c|c|}
\hline \multirow{2}{*}{ Preferred term } & \multicolumn{2}{|c|}{$\begin{array}{l}\text { New/ Fasted } \\
(n=30)\end{array}$} & \multicolumn{2}{|c|}{$\begin{array}{l}\text { New/ Semi-fed } \\
\quad(n=30)\end{array}$} & \multicolumn{2}{|c|}{$\begin{array}{l}\text { Current/ Fasted } \\
\qquad(n=30)\end{array}$} & \multicolumn{2}{|c|}{$\begin{array}{l}\text { Current/ Semi-fed } \\
\qquad(n=30)\end{array}$} & \multicolumn{2}{|c|}{$\begin{array}{l}\text { Overall } \\
(n=30)\end{array}$} \\
\hline & n $(\%)^{[1]}$ & $n A E^{[2]}$ & n $(\%)^{[1]}$ & $n A E^{[2]}$ & n $(\%)^{[1]}$ & $n A E^{[2]}$ & $n(\%)^{[1]}$ & $\mathrm{nAE}^{[2]}$ & n $(\%)^{[1]}$ & $n A E^{[2]}$ \\
\hline Abdominal Pain & $1(3.3)$ & 2 & $1(3.3)$ & 1 & $2(6.7)$ & 2 & $2(6.7)$ & 2 & $2(6.7)$ & 7 \\
\hline Abdominal Pain Upper & 0 & 0 & $1(3.3)$ & 1 & $1(3.3)$ & 1 & 0 & 0 & $2(6.7)$ & 2 \\
\hline Nausea & 0 & 0 & $1(3.3)$ & 1 & $1(3.3)$ & 1 & 0 & 0 & $2(6.7)$ & 2 \\
\hline Headache & $1(3.3)$ & 1 & $1(3.3)$ & 1 & $2(6.7)$ & 2 & $2(6.7)$ & 2 & $6(20.0)$ & 6 \\
\hline Dizziness & 0 & 0 & $1(3.3)$ & 1 & $1(3.3)$ & 1 & $2(6.7)$ & 3 & $3(10.0)$ & 5 \\
\hline Burning Sensation & $1(3.3)$ & 1 & 0 & 0 & 0 & 0 & $1(3.3)$ & 1 & $2(6.7)$ & 2 \\
\hline Oropharyngeal pain & $1(3.3)$ & 1 & 0 & 0 & 0 & 0 & $2(6.7)$ & 2 & $3(10.0)$ & 3 \\
\hline
\end{tabular}

$[1] \mathrm{n}(\%)=$ Number (percent of subjects)

[2] $n A E=$ Number of adverse events

Table 4: Most frequently occurring AEs in the study (overall incidence of occurrence $\geq 5 \%$ ) listed.

both the fasted $(\mathrm{P}<0.0001)$ and semi-fed states $(\mathrm{P}=0.0136)$. Based on $\mathrm{T}_{4}$, paracetamol absorption was twice as fast for the new formulation as compared to the conventional formulation in both fasted and fed states.

\section{Safety results}

All treatments were well tolerated, most AEs were mild in intensity and none were severe. There were a total of $50 \mathrm{AEs}$ reported in the study by 15 subjects. Most of them (48) were mild in intensity and two of 
them were moderate. Fifteen of them were deemed as treatment related. The reported AEs included nervous system disorders (e.g. dizziness, tremor), gastrointestinal disorders (e.g. abdominal pain), vascular disorders (e.g. hot flush), and psychiatric disorders (e.g. anxiety). No serious AEs were observed in the study. The most frequently occurring AEs (overall incidence of occurrence $\geq 5 \%$ ) in the study are listed in Table 4 . In the fasted state, 10 treatment emergent AEs were reported by 5 of 30 subjects (17\%) following the new formulation, and 8 treatment emergent AEs were reported by 6 of 30 subjects $(20 \%)$ following currently marketed conventional product. In the semi-fed state, 15 treatment emergent AEs were reported by 4 (13\%) of the 30 subjects following the new formulation treatment, and 17 treatment emergent AEs were reported by nine (30\%) of the 30 subjects following the conventional product.

\section{Discussion}

Pharmaceutical products are often reformulated in an effort to achieve better therapeutic activity in the shortest possible time by using smallest quantity of drug administered by the most suitable route. When absorption or bioavailability is related to dissolution rate, increased dissolution rate can enhance absorption to give faster onset of action [12]. This study was conducted to evaluate a new paracetamol/caffeine formulation, formulated using OPTIZORB ${ }^{\circledR}$ technology as compared to the conventional formulation. It was expected that this new product would demonstrate a bioequivalence with the conventional formula, but have comparatively faster absorption of both paracetamol and caffeine.

Caffeine has been added as an analgesic adjuvant to many marketed formulations containing acetaminophen, aspirin, and other non-steroidal anti-inflammatory drugs (NSAIDs), and has been in use for some time. In a meta-analysis of 26 clinical studies that examined the adjuvant analgesic effect of caffeine, over-the-counter analgesics containing caffeine (i.e, paracetamol plus caffeine, aspirin plus caffeine) gave a relative potency estimate of 1.41 vs. products without caffeine. With specific relevance to paracetamol plus caffeine vs. paracetamol alone, the relative potency estimate was 1.37 [13]. More recent clinical studies on adjuvant actions of caffeine suggest that caffeine was useful for enhancing relief of headache pain [14-16] and menstrual pain [17].

For the bioequivalence portion of the study, $\mathrm{AUC}_{0-\infty}, \mathrm{AUC}_{0-\mathrm{t}}$, and $\mathrm{C}_{\max }$ values were compared between these two formulations. According to the guideline of Committee for Proprietary Medical Products (CPMP) [18], new PANADOL ${ }^{\circledR}$ EXTRA ADVANCE and currently marketed PANADOL EXTRA ${ }^{\circledR}$ were bioequivalent for the $\mathrm{AUC}_{0-\mathrm{t}}$ and $\mathrm{AUC}_{0-\infty}$ of paracetamol and caffeine, in both the fasted and semi-fed states. For the $\mathrm{C}_{\max }$ of paracetamol and caffeine, the new formulation and the currently marketed product were bioequivalent in semi-fed state and fasted state, except that in the fasted state paracetamol $\mathrm{C}_{\max }$ was significantly higher following the new formulation treatment. This is indicative of the food effect on paracetamol absorption which is observed in other PK studies for paracetamol $[11,19,20]$. However the higher paracetamol $\mathrm{C}_{\max }$ values observed are within ranges previously observed in clinical studies with paracetamol and are not likely of clinical significance. In addition, the observed mean $\mathrm{C}_{\max }$ value $(17 \mathrm{ug} / \mathrm{ml})$, as well as the range of individual $\mathrm{C}_{\max }$ values, for the new formulation are approximately ten times lower than the plasma levels of paracetamol $(\geq 200 \mathrm{ug} / \mathrm{ml})$ associated with overdose liver damage [21].
As the new formulation was expected to achieve a significantly greater early absorption due to faster dissolution rate, $\mathrm{AUC}_{0-30 \mathrm{~min}}$ $\mathrm{AUC}_{0-60 \mathrm{~min}}$ and $\mathrm{T}_{\max }$ were evaluated in both the fasted and semi-fed states. New PANADOL ${ }^{\circledR}$ EXTRA ADVANCE showed significantly faster early absorption of paracetamol and caffeine compared to the currently marketed product, as measured by the early absorption parameters of $\mathrm{AUC}_{0-30 \mathrm{~min}}$ and $\mathrm{AUC}_{0-60 \mathrm{~min}}$, in both the fasted and semifed states. The new formulation also showed significantly shorter $\mathrm{T}_{\max }$ for both paracetamol and caffeine as compared to the conventional caplets in both the fasted and semi-fed states. These data indicate that the new formulation could potentially have similar overall analgesic efficacy to the current formulation, but with significantly faster onset.

\section{Conclusion}

The new PANADOL ${ }^{\circledR}$ EXTRA ADVANCE formulation showed bioequivalence to the currently marketed conventional paracetamol/ caffeine formulation in terms of the extent of absorption in both the fasted and semi-fed states. Also the new formulation showed significantly faster early absorption and twice as fast to reach the therapeutic level in comparison to the currently marketed product. The new formulation was safe and well tolerated.

\section{Acknowledgements}

The authors would like to thank Drs. James Otto and Geoff Clarke for valuable discussion and Ms. Priyanka Tiwari for the assistance in preparation of this manuscript.

\section{References}

1. Botting RM (2000) Mechanism of action of acetaminophen: is there a cyclooxygenase. Clin Infect Dis 31: S202-210.

2. Konturek SJ, Obtulowicz W, Kwiecien N, Oleksy J (1984) Generation of prostaglandins in gastric mucosa of patients with peptic ulcer disease: effect of nonsteroidal antinflammatory compounds. Scand J Gastroenterol Suppl 101: 75-77.

3. Smith R (1998) Migraine relief with acetaminophen, aspirin, and caffeine abstract and commentary. JAMA 279: 1310

4. Sawynok J, Yaksh TL (1993) Caffeine as an analgesic adjuvant: a review of pharmacology and mechanisms of action. Pharmacol Rev 45: 43-85.

5. Lipton RB, Stewart WF, Ryan RE Jr, Saper J, Silberstein S, et al.(1998) Efficacy and safety of acetaminophen, aspirin, and caffeine in alleviating migraine headache pain: three double-blind, randomized, placebo-controlled trials. Arch Neurol 55: 210-217.

6. Ward N, Whitney C, Avery D, Dunner D (1991) The analgesic effects of caffeine in headache. Pain 44: 151-155.

7. Fisone G, Borgkvist A, Usiello A (2004) Caffeine as a psychomotor stimulant mechanism of action. CMLS 61: 857-872

8. Addicott MA, Yang LL, Peiffer AM, Burnett LR, Burdette JH, et al. (2009) The effect of daily caffeine use on cerebral blood flow: How much caffeine can we tolerate? Hum Brain Mapp 30: 3102-3114.

9. Ward N, Whitney C (1991) The analgesic effects of caffeine in headache. Pain 44:151-155.

10. Renner B, Clarke G, Grattan T (2003) Analgesic effects of paracetamol in comparison to its combination with caffeine. J Clin Pharmacol 43:1038.

11. Wilson CG, Clarke CP, Starkey YY, Clarke GD (2011) Comparison of a nove fast-dissolving acetaminophen tablet formulation (FD-APAP) and standard acetaminophen tablets using gamma scintigraphy and pharmacokinetic studies. Drug Dev Ind Pharm 37: 747-753.

12. Kumar UV, Naik VV, Rao YN, Reddy CG, Chowdhary KPR (2010) Formulation and Evaluation of Modified Release Carvedilol Tablets. Pharmanest 1: 83-87. 
Citation: Liu D, Kotler M, Sharples S (2011) Pharmacokinetic and Bioequivalence Study Evaluating a New Paracetamol/Caffeine Formulation in Healthy Human Volunteers. J Bioequiv Availab 3: 251-257. doi:10.4172/jbb.1000095

13. Laska EM, Sunshine A, Mueller F, Elvers WB, Siegel C, et al. (1984) Caffeine as an analgesic adjuvant. JAMA 251: 1711-1718.

14. Migliardi JP, Armellion JJ, Friedman M, Gillings DB, Beaver WT (1994) Caffeine as an analgesic adjuvant in tention headache. Clin Pharmacol Ther 56: 576586 .

15. Zhang WY (2001) A benefit-risk assessment of caffeine as an analgesic adjuvant. Drug Saf 24:1127-1142.

16. Renner B, Clarke G, Grattan T, Beisel A, Mueller C, et al. (2007) Caffeine accelerates absorption and enhances the analgesic effect of acetaminophen. $J$ Clin Pharmacol 47: 715- 726.

17. Ali A, Burnett I, Eccles R, North M, Jawad M, et al. (2007) Efficacy of a paracetamol and caffeine combination in the treatment of the key symptoms of primary dysmenorrhoea. Curr Med Res Opin 23: 841-851.

18. CHMP (2011) Guideline on the investigation of bioequivalence.

19. Divoli M, Greenblatt DJ, Ameer B, Abernethy DR (1982) Effect of food on acetaminophen absorption in young and elderly subjects. J Clin Pharmacol 22 : 571-576.

20. Jaffe JM, Collaiza JL, Barry H (2006) Effects of dietary components on GI absorption of acetaminophen tablets in man. J Pharm Sci 60: 1646-1650.

21. Prescott LF (2001) Paracetamol (acetaminophen). A critical bibliographic review. Taylor \& Francis, London. 